\title{
ReviewArticle
}

\section{Corona Virus; A Comprehensive Overview About Its Life Cycle and Pathogenecity}

\author{
Nighat Zia-ud-Den ${ }^{1}$, , Amer Jamil ${ }^{2}$, Muhammad Imran Kanjal ${ }^{3}$, Sobia Ambreen ${ }^{2}$, Zirwah Rizwan $^{1}$ \\ ${ }^{1}$ Department of Biochemistry, Government College University Faisalabad, Faisalabad, Pakistan \\ ${ }^{2}$ Department of Biochemistry, University of Agriculture, Faisalabad, Pakistan \\ ${ }^{3}$ Department of Chemistry, Government College University Faisalabad, Faisalabad, Pakistan
}

Emailaddress:

nighatzia16@gmail.com (N. Zia-ud-Den)

${ }^{*}$ Correspondingauthor

\section{To cite this article:}

Nighat Zia-ud-Den, Amer Jamil, Muhammad Imran Kanjal, Sobia Ambreen, Zirwah Rizwan. Corona Virus; A Comprehensive Overview About Its Life Cycle and Pathogenecity. American Journal of Biomedical and Life Sciences. Vol. 8, No. 3, 2020, pp. 54-59.

doi: $10.11648 /$ j.ajbls.20200803.12

Received: April 7, 2020; Accepted: April 27, 2020; Published: May 28, 2020

\begin{abstract}
COVID-19, a rapidly spreading new strain of coronavirus, has affected more than 150 countries and received worldwide attention. The lack of efficacious drugs or vaccines against SARS-CoV-2 has further worsened the situation. Thus, there is an urgent need to boost up research for the development of effective therapeutics and affordable diagnostic against COVID-19. In this time of health crisis, it is the duty of scientific research community to provide alternative, effective and affordable strategies to vaccinate human bodies against viral infections-COVID-19 based on focused experimental approaches. Corona virus $(\mathrm{CoV})$ is forward RNA virus on its surface, containing stick-shaped spikes. It is an undesirable broad genome of RNA, with an indefinite replication system. In mammals, birds, pigs and chickens, corona virus cause various infections. This triggers the pathogens of the upper respiratory tract, which can lead to death due to breathing illnesses. In this article the author briefly justify sudden occurrence of this highly pathogenic extreme lung disease and recently discovered in Middle East respiratory syndrome corona virus (MERS-CoV). This is review article are awareness about the CoVID-19 infection and its out break throughout the world. In this article brief history about life cycle, pathogenecity and transmittance of corona virus given.
\end{abstract}

Keywords: Corna Virus, Genomic Structure, Life Cycle, Transmittance, Treatment and Prevention

\section{History of Origin}

In 1960, the very first outbreak of corona virus was identified with cold symptoms. Roughly, 500 patients have been reported as pneumonia like conditions, according to the 2001 Canadian report. Numerous studies were reported in 2003 with evidence of expanding the corona to different states such as Hong Kong, United States, Singapore, Thailand and China. Several reports of extreme acute respiratory syndrome induced by corona were recorded in 2003 and their death rate around 1000 patient in March to June 2003. Numerous infectious victims and deaths were reported in Saudi Arabian in 2012 [6-21]. COVID-19 was first detected and identified from the monopoly on the pneumonia belongs to China, Wuhan [5-6]. Major sudden occurrence was found in Hong Kong, Singapore and China and in many countries of Southeast Asia and in North America Spreading of this disease due to high level of social contact through community. After a long time now again in city of Wuhan (China) outbreak of this disease occurred in December 2019. Approximately, nCoV-19 has been spread to more than a hundred counties worldwide. Among all countries, 80,824 (54.02\%) nCoVD-19 confirmed cases are found and its rate continuously increased.

\section{Morphology of Corona Virus}

This is spherical to pleomorphic having 100 to $300 \mathrm{~nm}$ size. 
This virion is sensitive to lipid solvent treatment, formaldehyde, nonionic detergents and oxidizing agents. In nasal secretion, approximately hundred million genomes detected in one $\mathrm{mL}$ that cause severe infection. It is spread when a person meet nasal secretion. Incubation period of SAR coronavirus is 2 to 10 days.

\section{Classification}

Corona viruses are single standard RNA viruses covered

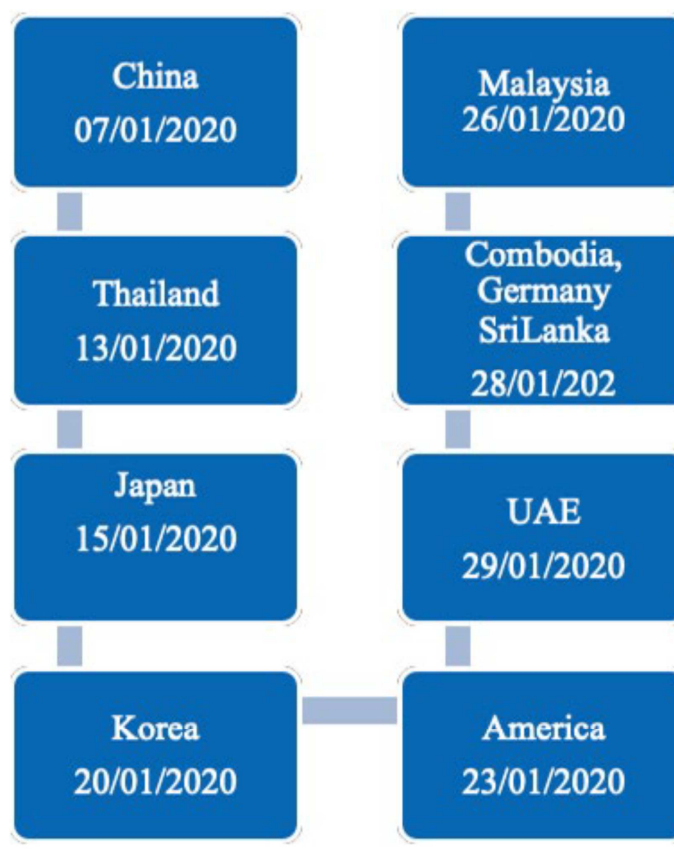

Figure 1. Spreading history of Corona virus. with glycoprotein covering that is club shaped. Corona viruses the biggest number of pathogens belongs to order of Nidovirales, comprising Cornoa-viridae, Arteriviridae and Roniviridae families. The Corona-virinae includes One of two subfamilies constitutes Corona-virinae i.e. the first is the family of Corona-viridae and while the other is the Toro-virinae. The Coronna-virinae is also segmented into 4 subgroups: the corona viruses alpha, beta, gamma and delta. The infections were initially classified into serological groups but now distinguished by phylogenetic groups [28].

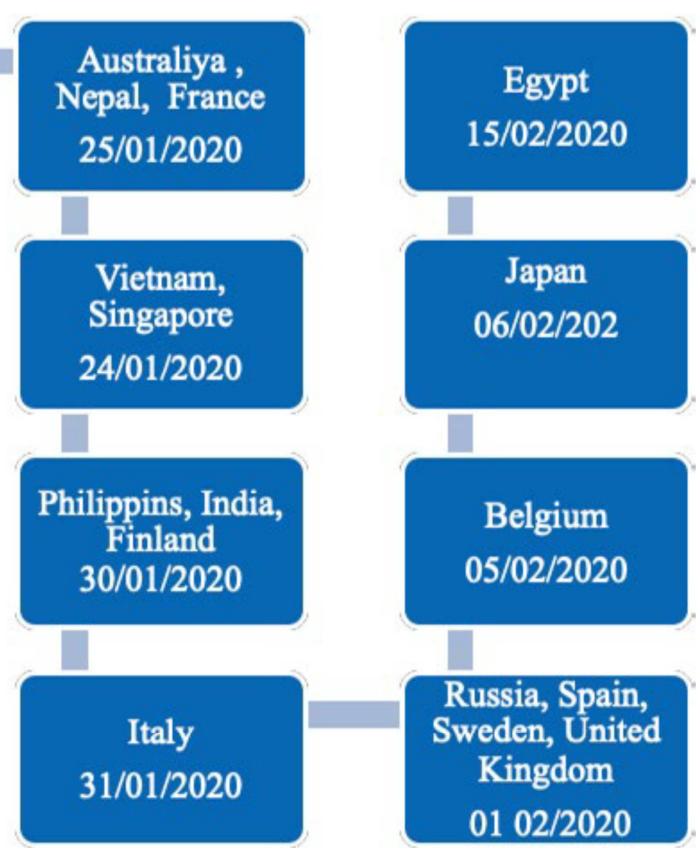

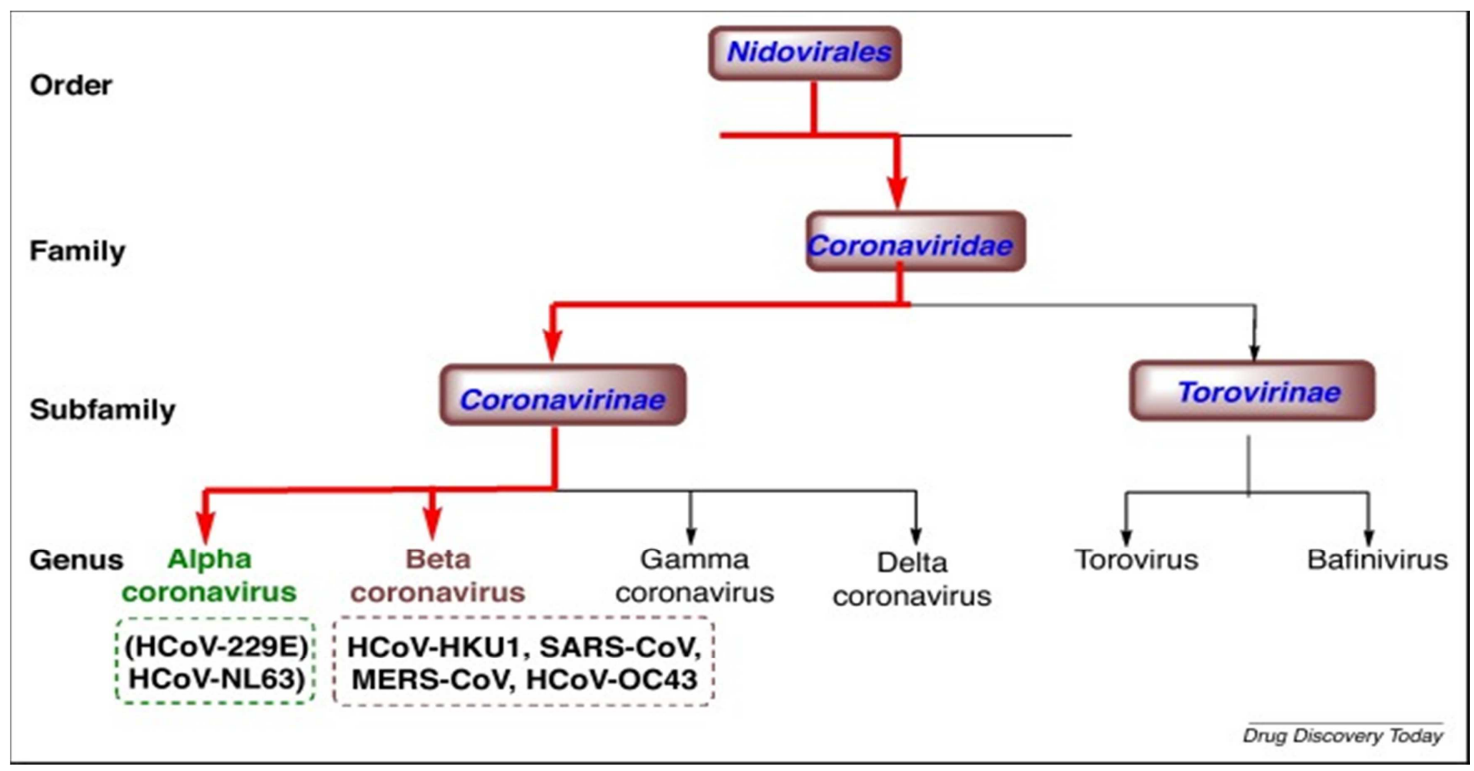

Figure 2. Classification of Corona virus.

\section{Genomic Organization}

Corona virus contains an undivided anti-sense RNA genome of approximately 30-kilo base pairs. The genetic material contains a 5 prime cap structure arrangement next to the 3 ' prime poly (A) tail, enabling it to behave as mRNA for translation of replicase polyproteins. The genes of replicase enzyme, which encodes un-structural proteins (nsps), holds 
$66 \%$ of the genome, about $20 \mathrm{~kb}$, rather than helper and extra proteins, which only account for about 10 kilo-base pair of the infectious (viral) genome. The 5 'end of the sequence comprises a precursor segment and an un-translated region (UTR), which composed of different stem-loop structures necessary for RNA replication and translation [3].
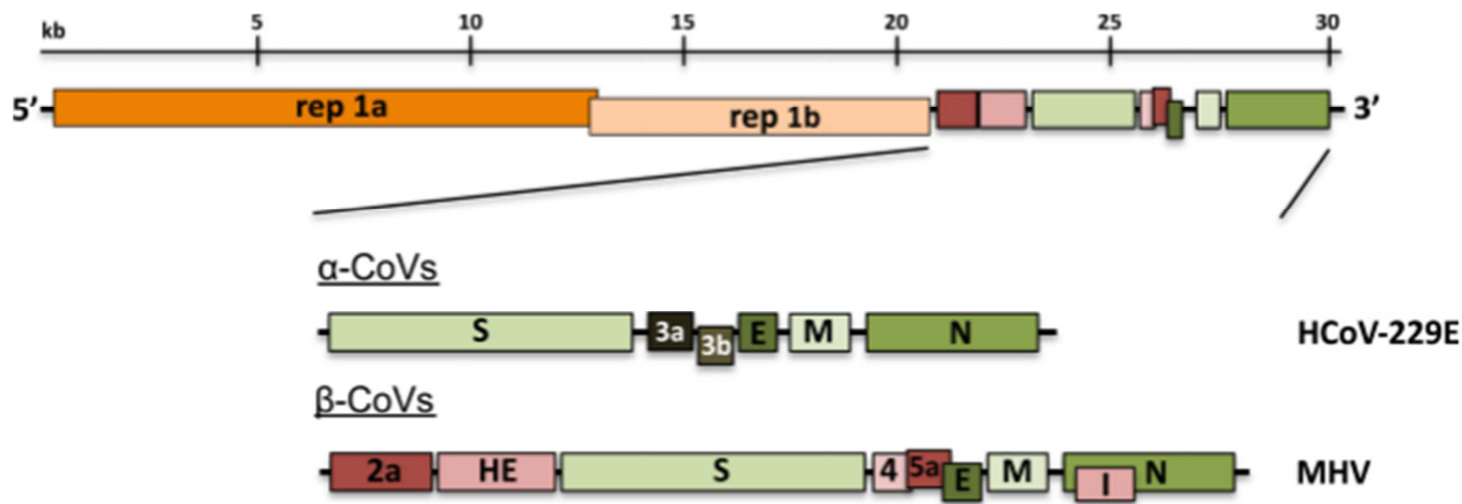

Figure 3. Genomic Orientation of Representative $\alpha$ and $\beta$ CoVIDs.

\section{Virion Structure}

Particles infected with corona viruses contain four major accessory pretentious components. They are spike proteins (S), membrane proteins (M), envelope proteins (E) and nucleocapsid proteins $(\mathrm{N})$, all are located at the three prime side of the viral genome. The S protein (about $150 \mathrm{kDa}$ ) enters the ER through the N-terminal symbol arrangement, and is tightly glycosylated by N. Infected homotrimers encoding the $\mathrm{S}$ protein constitute an intact spike structure outside the infection [4][9]. Trimeric S glycoproteins are class I combinatorial proteins and are linked to host receptors [7]. In most, but not all, coronaviruses, $\mathrm{S}$ is divided into two separate polypeptides by host cell furin-like proteases, designated S1 and S2 [1, 17]. S1 constitutes the huge receptor-restricted space of the S protein, while S2 constitutes the stem of spike-like atoms [8]. The protein $\mathrm{M}$ in a viron is an active helper protein having size of approximately 25 to 30 kilo Dalton with three trans-membrane domains [2] and is assumed to have a shape of virion particle. It has a small extracellular $\mathrm{N}$-terminal glycoprotein region and a broader C-terminal domain that expanding 6 to 8 nano-meter into infectious molecules [19]. A small amount of E protein having 8 to 12 $(\mathrm{kDa})$ sizes was found inside the virion. Corona viruses have very different $\mathrm{E}$ proteins, but have a typical engineering design [12]. The $\mathrm{N}$ protein comprises the main proteins found in the nuclear envelop [27]. It contains two separate spaces, an N-terminal side (NTD) and a C-terminal side (CTD), both are appropriate for RNA in vitro restriction, but each space needs different components to bind RNA. In subset of beta corona virus a fifth helper protein, hem-agglutinin esterase (HE), is found. This protein acts as of hem-agglutinin, connects to sialic acid to surface glycoproteins, having acetyl esterase movement [14].

LifeCycle

Attachment and Entry

The SARS-CoV S protein binds to its cellular receptor ACE2 and its life cycle begins. The conformational shift S protein occurred when receptor binds that permit the viral envelop to fuse through endosome pathway with the cell membrane. The possible connection among the virion and host cell is triggered by interaction between $\mathrm{S}$ protein and its receptor. Location of the receptor restriction / receptor-binding domain (RBD) within the corona virus $\mathrm{S} 1$ region. The changes in the $\mathrm{S}$ protein depend on the infection, some of which have RBD (MHV) at the N-side of S1 and others (SARS-CoV) have RBD at the C-terminus of S1 [6-16]. The $\mathrm{S}$ protein / receptor junction is an important determinant of corona virus contamination of host animal species and further controlling the tropism of infected tissues. Many corona viruses use peptidase as their cellular receptor.

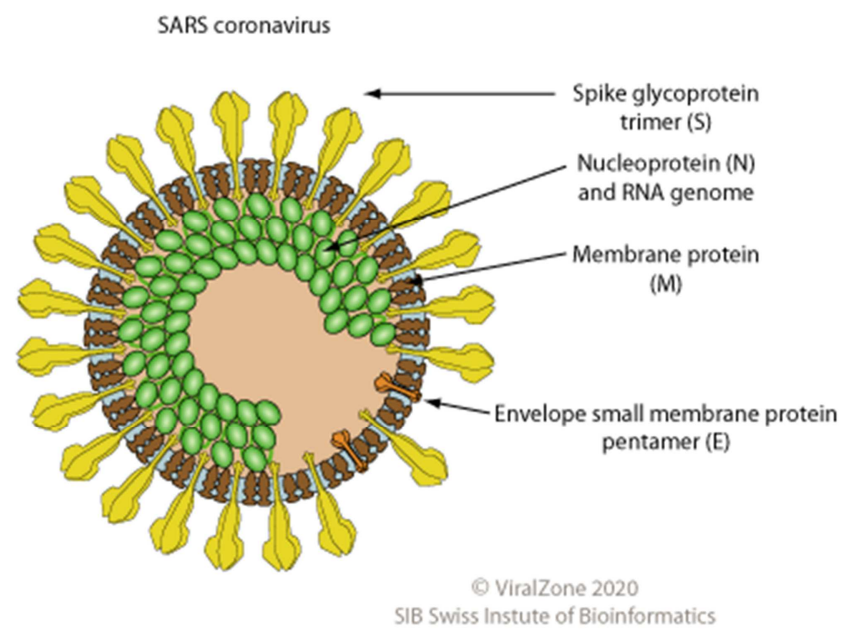

Figure 4. Structure of corona virus.

Expression of Replicase protein

The first stage of the corona virus life cycle is the release of RNA into host cells, causing interpretation because it has the replicase property of virion genome RNA. This replicase protein contains two huge open reading frames (ORFs) i.e. rep1a and rep1b, that showed two common proteins, ppla and pplab (Figure 4). The infection used harmful inherited sequences (5'-UUUAAAC-3') to convey the two polyproteins, which cause the ribosome structure to shift from repla to the 
rep1b ORF. Genomic RNA is incorporated into ppla and viral replicase, which are then breakdown into small pieces, by viral proteases.

Replication and Transcription

At the same time, polymerases, which generate subgenomic mRNAs set by linear transposition, are gradually converted into appropriate infectious proteins. The viral RNA production results in the viral replicase structure being translated and distributed. The binding synthesis of viral RNA produces genomic RNA and subgenomic RNA. Subgenomic RNA is packed as mRNA, present in the auxiliary and ruffle quantity downstream of the replicase polyprotein. All sense sub-genomic RNAs have a 3 'common end with the complete-length viral genome, thus making several stable RNAs which is special property that requires Nidovirales [3]. Both genomic and sub-genomic RNA generated through sense strand intermediates. This harmful intermediate in the chain are around $1 \%$ of their positive partners and includes both polyuridine and aggression to the arrangement of the pioneers [2-1].

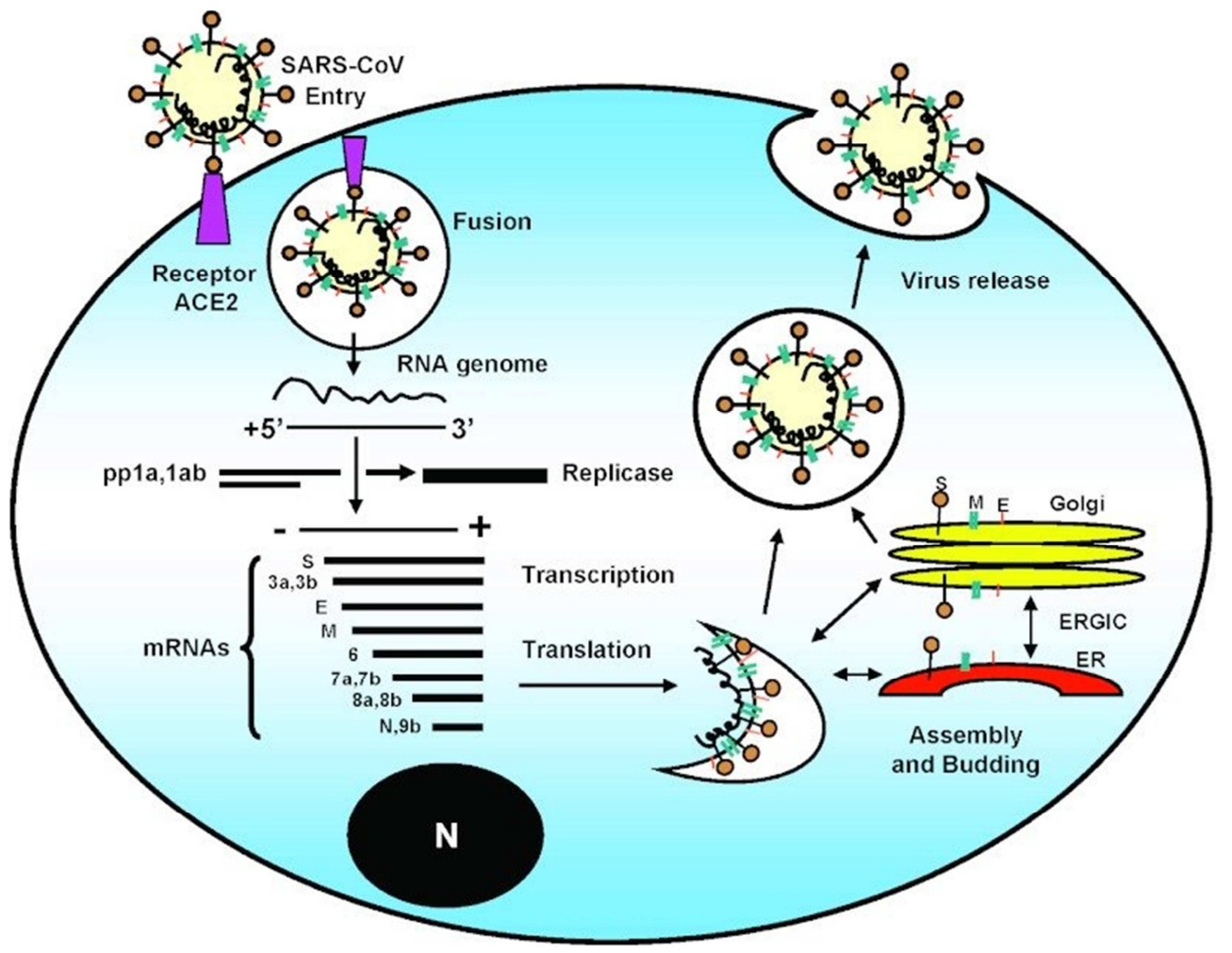

Figure 5. Life cycle of SARS-corona viruses.

Congregation and Discharge

The viral basic proteins $\mathrm{S}, \mathrm{E}$ and $\mathrm{M}$ are perceived and incorporated in endoplasimicc reticulum (ER) after amplification and combining of subgenomic RNA. These proteins pass across the epithelial pathway into the endoplasmic reticulum-Golgi apparatus (ERGIA) [15-23]. As a result, infectious proteins and genomic RNA are collected into viral in endoplasimic reticulum and Golgi apparatus, which gradually mature into the matrix of endoplasimic reticulum-golgi complex, which is transported through organelle and excreted from the cell. ACE2, angiotensin conversion to catalyst 2; ER, endoplasmic reticulum; ERGIC, ER-Golgi transition. There, the viral genome encapsulated by the $\mathrm{N}$ protein germinated into the ERGIC layer containing the viral basic protein, and framed the experienced virions as a framework [2-3].

HumanCoronaViruses

Only the corona virus was supposed to be source of moderate self-restricting lung infection in humans prior to SAR-corona viruses' outbreak [24]. Among these human corona viruses are $\alpha$-corona viruses (HCoV-229E, V-NL63) while the other are $\beta$-corona viruses (HCoV-OC43, V-HKU1). Approximately 50 years ago, HCoV-229E and HCoV-OC43 were separated [5-18], while HCoV-NL63 and HCoV-HKU1 were only in SARS-corona virus outbreaks [25-26]. In new born, elderly and the people with underlying conditions, they cause more severe illness and decrease the frequency of lower respiratory tract infections in this population. SARS-CoV is ineffective in distribution, since it is transmitted after the initiation of disease and by direct contact with infected person. Therefore, outbreaks are mainly controlled in homes and medical institutions [20], but in a few cases of super transmission, one person can infect multiple contacts due to high viral load or increased capacity.

Transmittance

SARS-CoV transmits essentially secretions (respiratory discharges) and near person to-individual communication. Individuals may get the infected via close contact with the victim who seems to have viral signs such as coughing and sniffling. The corona virus was typically transmitted via zoonotic droplets in the air. Virus circulated in the epithelial tissue of oral cavity, including tissue and cellular damage and 
inflammation at the origin of contact. For patients of SAR-CoV, it may occur for respiratory pollutants, stools, pees and sweats. Since coming in contact, the viruses stick to its angiotensin receptor, which interacts with respiratory system on the vital objective cells, pneumocytes and enterocytes as well as other sensitive cells, such as gastrointestinal mucosal cells, renal tubular mucosal cells, cerebral neurons and resistant cells. When these cells infiltrate, the infection mimics and is discharged to new target cell. The rate of development and action of anti-inflammatory chemokines and cytokines is extremely high causing considerable damage to lung tissue resulting in typical pneumonia with respiratory disintegration and failure [22].

Diagnosis, Treatment and Prevention

As a rule of self-regulating pollution, the coronavirus conclusion is meaningless because the disease usually continues to develop. Regardless, in some clinical and veterinary settings or epidemiological examinations, it may be important to distinguish between etiologists. Analysis is also important in areas where extreme corona virus outbreaks occur, including those in the Middle East where MERS-CoV is endemic [4]. The case specific findings will direct overall health efforts to contain the outbreak. Controlling these infections and supplying food, it is also necessary to evaluate serious veterinary CoV-caused diseases (such as PEDV and IBV). RT-PCR has become a decision-making tool to for human $\mathrm{CoV}$ identification $[10,11]$. Serum testing is necessary in circumstances where RNA seems to be impossible to isolate and never exist again, and for epidemiological investigations. Because of shortage of appropriate therapies or immunizations, a strong overall health observation system remains good to monitor human corona virus quick suggestive screening and isolation where possible. For global events, collaboration between managers, general health professionals, and social insurance providers is essential. During rapidly spreading veterinary outbreaks, such as PEDV, increasingly aggressive estimates, such as the elimination of entire herds, may be important to stop the spread of these deadly infections.

Management and Vaccination

Currently no special vaccine exists for treatment of this viral infection. The recovery approach practiced by health care practitioners is just positive counseling. Helpful treatment involves alpha-blocker and antihistamine drugs administration, intake of plenty of water, maintained proper breathing rate and use of antibiotics during bacterial or viral infections.

Conclusion

Recent work on corona virus will persist to explore other details of proliferation and pathophysiology of viruses. Understanding about the potential of such diseases to restarts between human beings, triggering disease in another person as well as identifying the vital corona virus would significantly help to execute when and where plague could occur. Considering the bats appears to be notable reservoir for this disease, which will important to know whether remain carefully separate from medically noticeable illnesses and work, hard to contaminate them. Furthermore, the vast number of non-basic and extra proteins produced by these infections remains uncharacterized and do not have any known capabilities. Such assessment would contribute to a substantial raise in the number of relatively valuable illness aid. Additionally, in advanced eukaryotes, there are large number of special catalysis encoded by corona viruses such as ADP-ribose-1 phosphatase, which renders their work significant for explaining the general parts of atomic science and organic chemistry. The specular highlights will provide a structure for recognizing the abnormal processes used by these infections for replication of RNA. Eventually, instruments that describe how corona viruses cause disease and recognize the resistant pathological response of host will improve our ability to plan for protection and immunity significantly. According to the recommendations of WHO and the ECDC, stay away in contact with the ill person as well as to minimize the market or public place whenever necessary. There is no anti-corona virus vaccine to prevent or treat however some studies need in support of therapy and future work required to fight with corona virus. Until only ' Rescue is space.

\section{Conflict of Interest}

All the authors do not have any possible conflicts of interest.

\section{Acknowledgements}

The author highly acknowledged this work to its respectable teachers and provide brief and general information about the outbreak of 2019 n-CoVID.

\section{References}

[1] Abraham, S., T. E. Kienzle, W. Lapps, W and D. A. Brian. 1990 Deduced sequence of the bovine coronavirus spike protein and identification of the internal proteolytic cleavage site. Virology. 176 (1): 296-301.

[2] Armstrong. J., H. Niemann, S. Smeekens, P. Rottier and G. Warren. 1984. Sequence and topology of a model intracellular membrane protein, E1 glycoprotein, from a coronavirus. Nature. 308 (5961): 751-752.

[3] Barcena, M., G. T. Oostergetel, W. Bartelink, F. G. Faas, A. Verkleij, P. J. Rottier, A. J. Koster and B. J. Bosch. 2009. Cryo-electron tomography of mouse hepatitis virus: Insights into the structure of the coronavirion. Proceedings of the National Academy of Sciences of the United States of America. 106 (2): 582-587.

[4] Beniac, D. R., A. Andonov, E. Grudeski and T. F. Booth. 2006. Architecture of the SARS coronavirus prefusion spike. Nature structural \& molecular biology. 13 (8): 751-752.

[5] Bradburne, A. F., M. L. Bynoe and D. A. J. Tyrell. 2006. Effects of a "new" human respiratory virus in volunteers. Br Med J. 3: 767-769.

[6] Centers for Disease Control and Prevention (CDC). Update: Outbreak of severe acute respiratory syndrome--worldwide, 2003. MMWR Morb Mortal Wkly Rep. 2003; 52 (12): 241-6. 
[7] Cheng, P. K., A. D. Wong, L. K. Tong, S. M. Ip, A. C. Lo, C. S. Lau, E. Y. Yeung and W. W Lim. 2004. Viral shedding patterns of coronavirus in patients with probable severe acute respiratory syndrome. Lancet. 363 (9422): 1699-1700.

[8] Collins, A. R., R. L. Knobler, H. Powell and M. J. Buchmeier, 1982. Monoclonal antibodies to murine hepatitis virus-4 (strain JHM) define the viral glycoprotein responsible for attachment and cell--cell fusion. Virology. 119 (2): 358-371.

[9] de Groot, R. J., W. Luytjes, M. C. Horzinek, B. A. van der Zeijst, W. J. Spaan and J. A. Lenstra. 1987. Evidence for a coiled-coil structure in the spike proteins of coronaviruses. J Mol Biol. 196 (4): 963-966.

[10] Delmas. B and H. Laude. 1990. Assembly of coronavirus spike protein into trimers and its role in epitope expression. Journal of virology. 64 (11): 5367-5375.

[11] Emery, S. L., D. D. Erdman, M. D Bowen, B. R. Newton, J. M. Winchell, R. F. Meyer, S. Tong, B. T. Cook, B. P. Holloway, K. A McCaustland, P. A. Rota, B. Bankamp, L. E. Lowe, T. G. Ksiazek, W. J. Bellini and L. J. Anderson. 2004. Real-time reverse transcription-polymerase chain reaction assay for SARS-associated coronavirus. Emerging infectious diseases. 10 (2): 311-316.

[12] Gaunt, E. R., A. Hardie, E. C. Claas, P. Simmonds and K. E. Templeton. 2010. Epidemiology and clinical presentations of the four human coronaviruses 229E, HKU1, NL63, and OC43 detected over 3 years using a novel multiplex real-time PCR method. Journal of clinical microbiology. 48 (8): 2940-2947.

[13] Godet, M., L. R. Haridon, J. F. Vautherot and H. Laude. 1992. TGEV corona virus ORF4 encodes a membrane protein that is incorporated into virions. Virology. 188 (2): 666-675.

[14] Hamre. D., and J. J. Procknow. 2009. A new virus isolated from the human respiratory tract. Proceedings of the Society for Experimental Biology and Medicine Society for Experimental Biology and Medicine. 121 (1): 190-193.

[15] Klausegger, A., B. Strobl, G. Regl, A. Kaser, W. Luytjes and R. Vlasak. 1999. Identification of a coronavirus hemagglutinin-esterase with a substrate specificity different from those of influenza $\mathrm{C}$ virus and bovine coronavirus. Journal of virology. 73 (5): 3737-3743.

[16] Krijnse-Locker. J., M. Ericsson, P. J. M. Rottier and G. Griffiths 1994. Characterization of the budding compartment of mouse hepatitis virus: Evidence that transport from the RER to the golgi complex requires only one vesicular transport step. J Cell Biol. 124: 55-70.

[17] Kubo, H., Y. K. Yamada and F. Taguchi. 1994. Localization of neutralizing epitopes and the receptor-binding site within the amino-terminal 330 amino acids of the murine coronavirus spike protein. J Virol. 68: 5403-5410.

[18] Luytjes, W., L. S. Sturman, P. J. Bredenbeek, J. Charite, B. A. van der Zeijst, M. C. Horzinek and W. J. Spaan. 1987. Primary structure of the glycoprotein E2 of coronavirus MHV-A59 and identification of the trypsin cleavage site. Virology. 161 (2): 479-487.

[19] McIntosh, K., W. B. Becker and R. M. Chanock. 2006. Growth in suckling-mouse brain of "IBV-like" viruses from patients with upper respiratory tract disease. Proceedings of the National Academy of Sciences of the United States of America. 58: $2268-2273$

[20] Nal. B., C. Chan, F. Kien, L. Siu, J. Tse, K. Chu, J. Kam, I. Staropoli, C. B. Crescenzo, N. Escriou, S. van der Werf, K. Y. Yuen and R. Altmeyer. 2005. Differential maturation and subcellular localization of severe acute respiratory syndrome coronavirus surface proteins S, M and E. The Journal of general virology. 86 (Pt 5): 1423-1434.

[21] Peiris, J. S., K. Y. Yuen, A. D. Osterhaus and K. Stohr. 2003. The severe acute respiratory syndrome. The New England journal of medicine. 349 (25): 2431-2441.

[22] Sethna, P. B., M. A. Hofmann and D. A. Brian. 1991. Minus-strand copies of replicating coronavirus mRNAs contain antileaders. Journal of virology. 65 (1): 320-325.

[23] Sturman, L. S., K. V. Holmes, J. Behnke. 2000. Isolation of coronavirus envelope glycoproteins and interaction with the viral nucleocapsid. Journal of virology. 33 (1): 449-462.

[24] Tooze. J., S. Tooze and G. Warren. 1984. Replication of coronavirus MHV-A59 in sac- cells: determination of the first site of budding of progeny virions. European journal of cell biology. 33 (2): 281-293.

[25] Van der Hoek, L., K. Pyrc, M. F. Jebbink, W. Vermeulen-Oost, R. J. Berkhout, K. C. Wolthers, D. P. M. Wertheim-van, J. Kaandorp, J. Spaargaren and B. Berkhout. 2004. Identification of a new human coronavirus. Nat Med. 10 (4): 368-373.

[26] Van, der. Z. R., C. A. de Haan, and P. J. Rottier. 2003. The coronavirus spike protein is a class I virus fusion protein: structural and functional characterization of the fusion core complex. J Virol. 77 (16): 8801-8811.

[27] Woo, P. C., S. K. Lau, C. M. Chu, K. H. Chan, H. W. Tsoi, Y. Huang, B. H. Wong, R. W. Poon, J. J. Cai, W. K. Luk, L. L. Poon, S. S. Wong, Y. Guan, J. S. Peiris and K. Y.

[28] World Health Organization. WHO Statement Regarding Cluster of Pneumonia Cases in Wuhan, China Geneva 2020 [updated 9 January 2020 and 14 January 2020]. Available from:

https://www.who.int/china/news/detail/09-01-2020-whostatem ent.regarding-cluster-of-pneumoniacases-in-wuhanchina.

[29] Yuen. 2005. Characterization andcomplete genome sequence of a novel coronavirus, coronavirus HKU1, from patients with pneumonia. Journal of virology. 79 (2): 884-895.

[30] Zhao, L., B. K. Jha, A. Wu, R. Elliott, J. Ziebuhr, A. E. Gorbalenya, R. H. Silverman and S. R. Weiss. 2012. Antagonism of the interferon-induced OAS-RNase L pathway by murine coronavirus ns 2 protein is required for virus replication and liver pathology. Cell host \& microbe. 11 (6): 607-616.

[31] Zhu N, Zhang D, Wang W, Li X, Yang B, Song J, et al. A Novel Coronavirus from Patients with Pneumonia in China, 2019. 24 January 2020. New England Journal of Medicine. 